\title{
The Complexity of Vascular and Non-Vascular Complications of Diabetes: The Hong Kong Diabetes Registry
}

\author{
Juliana C. N. Chan • Wingyee So $\cdot$ Ronald C. W. Ma • \\ Peter C. Y. Tong • Rebecca Wong • Xilin Yang
}

Published online: 12 April 2011

(C) The Author(s) 2011. This article is published with open access at Springerlink.com

\begin{abstract}
Diabetes is a complex disease characterized by chronic hyperglycemia and multiple phenotypes. In 1995, we used a doctor-nurse-clerk team and structured protocol to establish the Hong Kong Diabetes Registry in a quality improvement program. By 2009, we had accrued 2616 clinical events in 9588 Chinese type 2 diabetic patients with a follow-up duration of 6 years. The detailed phenotypes at enrollment and follow-up medications have allowed us to develop a series of risk equations to predict multiple endpoints with high sensitivity and specificity. In this prospective database, we were able to validate findings from clinical trials in
\end{abstract}

J. C. N. Chan - W. So $\cdot$ R. C. W. Ma $\cdot$ P. C. Y. Tong $\cdot$ X. Yang

Hong Kong Institute of Diabetes and Obesity,

Shatin, NT, Hongkong SAR

W. So

e-mail: wingyeeso@cuhk.edu.hk

R. C. W. Ma

e-mail: rcwma@cuhk.edu.hk

P. C. Y. Tong

e-mail: ptong@cuhk.edu.hk

$\mathrm{X}$. Yang

e-mail: yang.xilin@cuhk.edu.hk

J. C. N. Chan $\cdot$ W. So $\cdot$ R. C. W. Ma • P. C. Y. Tong $\cdot$ R. Wong

$\mathrm{X}$. Yang

Department of Medicine and Therapeutics, The Prince of Wales

Hospital, The Chinese University of Hong Kong,

Shatin, NT, Hongkong SAR

R. Wong

e-mail: wongymr@ha.org.hk

J. C. N. Chan $(\bowtie) \cdot$ P. C. Y. Tong

Qualigenics Diabetes Centre,

Hong Kong SAR, China

e-mail: jchan@cuhk.edu.hk real practice, confirm close links between cardiovascular and renal disease, and demonstrate the emerging importance of cancer as a leading cause of death. In addition to serving as a tool for risk stratification and quality assurance, ongoing data analysis of the registry also reveals secular changes in disease patterns and identifies unmet needs.

Keywords Diabetes · Comorbidities · Cancer - Registry · Chinese

\section{Introduction}

Diabetes has become a global epidemic in both developing and developed areas. In 2007, the International Diabetes Federation predicted that 170 million people would be diabetic and that $60 \%$ of those affected would be from Asia. However, national figures from China in 2007 and 2008 indicated that 97 million people had diabetes and 150 million people had prediabetes in China alone [1]. In May 2010, the United Nations passed a resolution in recognition of the burden of chronic diseases, including diabetes, heart disease, cancer and respiratory disease, on individuals, family, and society. Collectively, these chronic diseases explain $60 \%$ of global deaths, requiring urgent multi-sectorial efforts to combat these health threats [2].

In the past two decades, cohort studies, randomized controlled trials, and meta-analyses have confirmed the predictive values of many risk factors and the benefits of their modification on clinical outcomes. Yet, national and international surveys have persistently shown marked chasms between guidelines and practice. In the International Diabetes Mellitus Practice Survey (IDMPS), which enrolled 
more than 10,000 diabetic patients from countries outside the United States and Europe, over 30\% of patients had never been assessed for complications and risk factor control, only $20 \%$ to $30 \%$ were achieving recommended treatment goals (blood pressure [BP] $<130 / 80 \mathrm{~mm} \mathrm{Hg}$, low-density lipoprotein cholesterol [LDL-C] $<2.6 \mathrm{mmol} / \mathrm{L}$, and glycated hemoglobin $[\mathrm{HbA} 1 \mathrm{c}]<7 \%$ ), and less than $5 \%$ were achieving all three goals. The suboptimal adherence to recommended clinical procedures to detect risk factors and complications and low rates in attaining treatment goals were similar irrespective of health care settings (private vs public) and the experience of health care professionals (specialists vs general internists) $[3 \bullet]$.

\section{Phenotypic Heterogeneity of Diabetes and its Co-Morbidities}

Diabetes has many phenotypes due to complex interactions in genetic, epigenetic, perinatal, lifestyle, socioeconomic, and environmental factors that influence neurohormonal, metabolic, and cell signaling pathways. Apart from hyperglycemia due to varying degrees of insulin deficiency and resistance, these metabolic changes are often accompanied by risk factors such as obesity, hypertension, dyslipidemia, and inflammation. The result is widespread vascular and nerve damage. These diabetic phenotypes interact with external factors, including pharmacologic and non-pharmacologic interventions, in a non-linear and multiplicative manner to modify the clinical course with different presentations and outcomes.

\section{Challenges in Delivery of Diabetes Care}

Most national and international guidelines recommend comprehensive assessment for risk factors and complications in all diabetic patients at diagnosis and then at regular intervals thereafter. These procedures are important given the silent, progressive, but highly preventable nature of diabetic complications. However, without changing the logistics of health care delivery at the level of the clinic, it is often challenging or even impossible for a busy doctor with an average consultation time of 5 to $20 \mathrm{~min}$ to perform these assessments and manage the large amount of clinical information to make informed individualized decisions. Furthermore, patients with diabetes need to be educated about their unique risk profiles, and receive education, empowerment, and encouragement in order to enhance their self care and as well as achieve optimal adherence to treatment regimens. To achieve these cognitive, psychological, and behavioral changes, rapport between patients and the health care team is essential.

\section{Using a Trio Team to Establish the Hong Kong Diabetes Registry}

In 1995, motivated by the International Diabetes Federation St. Vincent's Declaration, which advocated the use of a protocol to benchmark quality of care in diabetes and to simultaneously promote patients' awareness of rights and roles [4], we introduced a series of changes to improve the delivery of diabetes service at the Prince of Wales Hospital, Hong Kong (Fig. 1).

1. We empowered our diabetes nurses to perform complication assessment using a protocol for independent collection of information in a structured manner, which allows doctors to maximize efficiency in decision making during routine visits.

2. We introduced a twice-weekly 4-h session led by one or two nurses supported by a health care assistant where 8 to 12 diabetic patients were given appointments. All patients were given instructions on the nature, purpose, and procedures of the comprehensive assessments, including attendance after $8 \mathrm{~h}$ of fasting.

3. We used structured assessment forms to enable doctors to provide medical and drug history upon referral, whereas nurses obtained personal and family history and activities of self care, followed by clinical measurements and phlebotomy.

4. We trained our nurses to use validated instruments to examine the feet (eg, graduated tuning fork, monofilament, Doppler scan) and eye (eg, fundus camera and Snellen's chart). In the absence of the latter instruments, a trained doctor would examine the fundus through dilated pupils using ophthalmoscope, which took less than $30 \mathrm{~min}$ for 10 to 12 patients. Before the patient left, he/she would provide a random or timed urinary collection for measurement of urinary albumin-creatinine ratio. All patients were asked to give written informed consent for data analysis for the purpose of conducting clinical research.

5. We designed a database with built in definitions for risk factors, complications and treatment goals, initially using Microsoft's dBASE (Redmond, WA) and later Microsoft Access, for data management and reporting. A dedicated clerical officer was responsible for data entry and management of the database.

6. On a weekly basis, a senior endocrinologist reviewed, on average 20 to 25 reports and recommended action plans to the referring doctor/team, including addition of insulin, renin angiotensin system (RAS) blockers, statins to intensify risk factor control, referral to educators or proposal of discharge, and follow up plan.

7. We arranged the same group of patients to return within 4 to 6 weeks for debriefing by our nurses and collection of an 
Fig. 1 Plan for using a team of doctors, nurses, and clerks to establish a diabetes registry for quality assurance and risk stratification to facilitate subsequent triage of patients to different clinic settings at the Prince of Wales Hospital of the Chinese University of Hong Kong since 1995

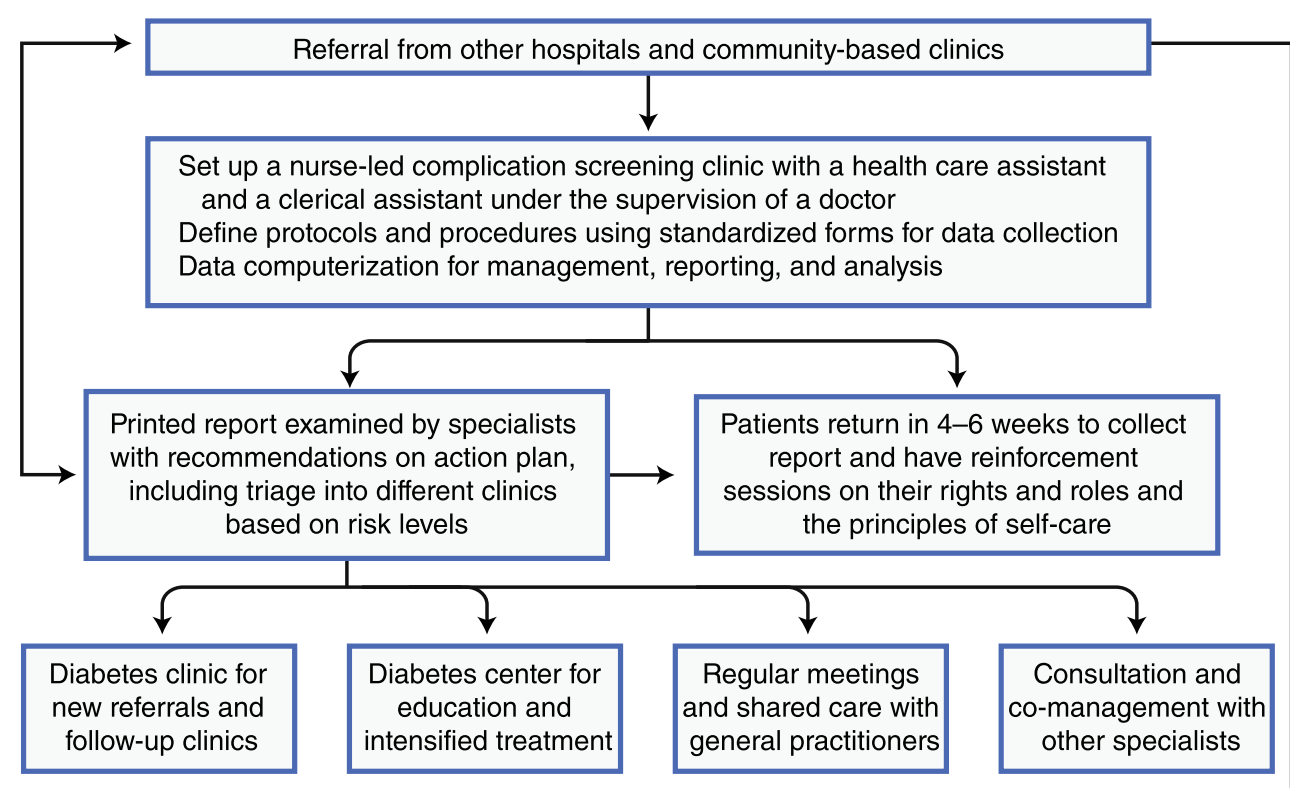

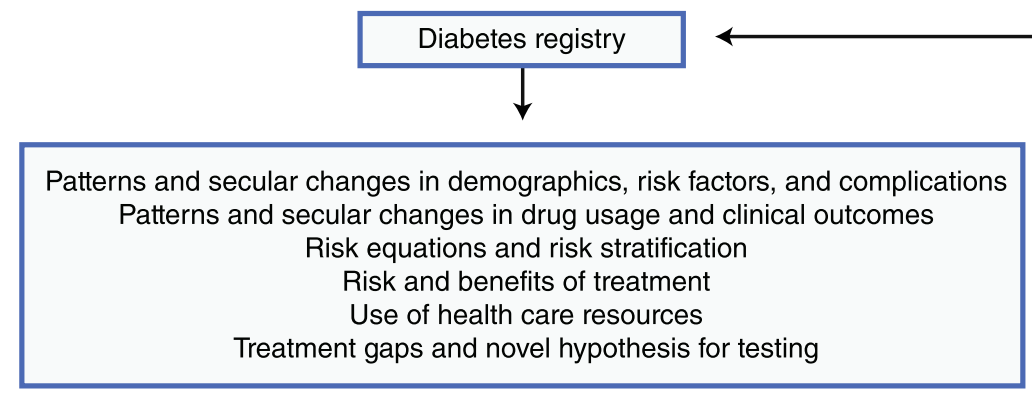

abbreviated "report card" listing risk factors, complications, treatment goals, and key messages on self-care.

8. According to the recommendations, the nurses then triaged patients to different care settings based on their risk profiles eg, hospital-based clinics for those with complications but stable control, community-based clinics for those without complications and stable control or specialist diabetes clinics for difficult-totreat patients with support from the nurse-led Diabetes Center. Before discharge to the community, patients were reminded of their rights and roles, techniques in self-blood glucose monitoring and interpretation, and the scheduled follow-up plan.

\section{Hong Kong Diabetes Risk Equations}

Although our Diabetes Registry was established as a quality improvement program, we made use of the universal health care system, which provides more than $95 \%$ of chronic care to patients in Hong Kong, to research into this prospective cohort. In Hong Kong, all patients attending public-funded clinics pay a nominal fee for consultations, evaluations, and medications.
From 1996, all critical clinical information including hospital discharges, outpatient clinic visits, procedures, and medications dispensed on site were gradually computerized by the Hong Kong Hospital Authority Clinical Management System (CMS). Using the unique Hong Kong Identity Card number, which is compulsory for all citizens, we were able to identify and censor clinical outcomes and use our comprehensive dataset to establish risk equations with $70 \%$ to $95 \%$ prediction accuracy or area under the receiver's operating characteristic curve.

Using this registry, which at the time of writing has accrued 2616 clinical events in 9588 Chinese type 2 diabetic patients with a follow up duration of 6 years, we have made important observations regarding the phenotypic heterogeneity and impacts of treatments on clinical outcomes. In this database, which exceeds 10,000 patients, only $3.7 \%$ had type 1 diabetes and the rest had type 2 diabetes. The mean age of the type 2 diabetic patients was 57.4 years, with a median 5 years of disease duration at the time of enrolment. The annual event rate (cardiovascular disease, end-stage renal disease [ESRD], cancer, and death) of this registry was 43.0 per 1000 person years, depending on the 
patients' risk profile. In contrast to whites in whom Coronary Heart Disease (CHD) is the main cause of death, $20 \%$ of our type 2 diabetic patients died with cancer (mainly liver, colorectal, renal, and respiratory tract), $20 \%$ with coronary heart disease (CHD) or heart failure, $11 \%$ with stroke, and $11 \%$ with respiratory disease $[5,6]$.

\section{Diabetic Kidney Disease}

Table 1 summarizes the predictors for each of these clinical outcomes, including all-cause death with albu- minuria and estimated glomerular filtration rate (eGFR), as the common risk factors for all endpoints. In agreement with other surveys [7,8], 16.2\% of our diabetic patients had macroalbuminuria and $25 \%$ had microalbuminuria, which were strongly predictive of cardiorenal events and all-cause mortality [9]. During the 6-year follow-up period, $19.1 \%$ of our patients developed diabetic kidney disease (DKD), defined as eGFR $<60 \mathrm{~mL} / \mathrm{min} / 1.73 \mathrm{~m}^{2}$. With the onset of DKD, these patients had further increase in cardiovascular risk due to retention of cytokines, heightened inflammatory responses, abnormal calcium-phosphate metabolism, pro-

Table 1 A summary of predictors for multiple clinical endpoints identified by the Hong Kong Diabetes Registry

\begin{tabular}{|c|c|c|c|c|c|c|c|}
\hline & $\mathrm{CHD}$ & $\begin{array}{l}\text { Heart } \\
\text { failure }\end{array}$ & Stroke & Chronic kidney disease & $\begin{array}{l}\text { End-stage renal } \\
\text { disease }\end{array}$ & Cancer & $\begin{array}{l}\text { All-cause } \\
\text { Death }\end{array}$ \\
\hline References & $\begin{array}{l}{[36,41,51,} \\
56-61]\end{array}$ & $\begin{array}{c}{[36,51,} \\
62]\end{array}$ & $\begin{array}{l}{[36,52} \\
63-66]\end{array}$ & $\begin{array}{l}{[9,13,39,40,46-50,59} \\
\quad 60,67]\end{array}$ & $\begin{array}{l}{[9,13,46-50,59,60} \\
\quad 68,69]\end{array}$ & $\begin{array}{l}{[25-28,32} \\
\quad 70,71]\end{array}$ & {$[5,9,11]$} \\
\hline Age & $\sqrt{ }$ & $\sqrt{ }$ & $\sqrt{ }$ & $\sqrt{ }$ & & & $\sqrt{ }$ \\
\hline Male gender & $\sqrt{ }$ & & & $\sqrt{ }$ & & & $\sqrt{ }$ \\
\hline Disease duration & $\sqrt{ }$ & & & $\sqrt{ }$ & & & \\
\hline Ever smoked & $\sqrt{ }$ & & & $\sqrt{ }$ & & & \\
\hline History of CHD & & $\sqrt{ }$ & $\sqrt{ }$ & & & & \\
\hline PVD & & & & & & & $\sqrt{ }$ \\
\hline BMI & & $\sqrt{ }$ & & & & $\sqrt{ }$ & $\sqrt{ }$ \\
\hline Central obesity & & & & $\sqrt{ }$ & & & \\
\hline Metabolic syndrome & & & & $\sqrt{ }$ & & & \\
\hline HbA1c & $\sqrt{ }$ & $\sqrt{ }$ & $\sqrt{ }$ & $\sqrt{ }$ & & $\sqrt{ }$ & \\
\hline Blood pressure & $\sqrt{ }$ & $\sqrt{ }$ & $\sqrt{ }$ & & & & \\
\hline LDL-C & $\sqrt{ }$ & $\sqrt{ }$ & $\sqrt{ }$ & & & $\sqrt{ }$ & \\
\hline Non-HDL-C & $\sqrt{ }$ & & & & & & \\
\hline Triglyceride & & & & $\sqrt{ }$ & & $\sqrt{ }$ & \\
\hline HDL-C & & & & $\sqrt{ }$ & & $\sqrt{ }$ & \\
\hline eGFR & $\sqrt{ }$ & & & $\sqrt{ }$ & & & $\sqrt{ }$ \\
\hline ACR & $\sqrt{ }$ & $\sqrt{ }$ & $\sqrt{ }$ & $\sqrt{ }$ & $\sqrt{ }$ & $\sqrt{ }$ & $\sqrt{ }$ \\
\hline White blood cell & $\sqrt{ }$ & & & & & $\sqrt{ }$ & \\
\hline Blood Haemoglobin & & $\sqrt{ }$ & & & & & $\sqrt{ }$ \\
\hline Blood & & & & & & & \\
\hline Hematocrit & $\sqrt{ }$ & $\sqrt{ }$ & & & $\sqrt{ }$ & & \\
\hline Erectile dysfunction & $\sqrt{ }$ & & & & & & \\
\hline Retinopathy & $\sqrt{ }$ & & & $\sqrt{ }$ & $\sqrt{ }$ & & \\
\hline $\begin{array}{l}\text { Chronic hepatitis B } \\
\text { infection }\end{array}$ & $\sqrt{ }$ & & & $\sqrt{ }$ & $\sqrt{ }$ & & \\
\hline History of cancer & & & & & & & $\sqrt{ }$ \\
\hline Non-use of statins & $\sqrt{ }$ & & & $\sqrt{ }$ & & $\sqrt{ }$ & \\
\hline $\begin{array}{l}\text { Non-use of RAS } \\
\text { inhibitors }\end{array}$ & & & & $\sqrt{ }$ & $\sqrt{ }$ & $\sqrt{ }$ & \\
\hline $\begin{array}{l}\text { Non-use of } \\
\text { metformin }\end{array}$ & & & & & & $\sqrt{ }$ & \\
\hline Genetic factors & $\sqrt{ }$ & $\sqrt{ }$ & $\sqrt{ }$ & $\sqrt{ }$ & $\sqrt{ }$ & & \\
\hline
\end{tabular}

ACR — albumin/creatinine ratio; BMI—body mass index; CHD — coronary heart disease; eGFR — estimated glomerular filtration rate; HbA1c_glycated hemoglobin; LDL-C-low-density lipoprotein cholesterol; HDL-C - high-density lipoprotein cholesterol; RAS - renin angiotensin system; PVD - peripheral vascular disease. 
pensity for vascular calcification, and anemia [10]. Compared to an annual event rate of $2 \%$ to $3 \%$ in those with eGFR $>60 \mathrm{~mL} / \mathrm{min} / 1.73 \mathrm{~m}^{2}$, patients with DKD had an annual event rate of $5 \%$ to $10 \%$ [11].

The importance of DKD in East Asian populations is evidenced by $40 \%$ to $55 \%$ of patients on dialysis in these countries having diabetes, compared to less than $30 \%$ in Western countries, such as Australia [12]. In a multinational study, Asian patients had higher prevalence of nephropathy than their white counterparts. This might be in part due to insufficient use of renoprotective drugs with only $20 \%$ of Asian patients in this global survey receiving reninangiotensin system (RAS) blockers compared to $30 \%$ in the white population [7]. In our registry, $25.1 \%$ of patients were treated with angiotensin-converting enzyme inhibitors (ACEI) or angiotensin II receptor blockers (ARB) at enrollment. After enrollment, $32.6 \%$ were started on these drugs, giving a total of $57.6 \%$ [9].

In addition to the possibility of delayed diagnosis or suboptimal care, chronic low grade infection such as hepatitis B virus (HBV) is present in $10 \%$ of the Chinese population and may play a causal role in glomerulonephritis. Using this prospective database, we have reported the fourfold increased risk of ESRD in HBV carriers compared to non-HBV carriers, after adjusting for other confounders [13]. In support of these findings, Chinese type 2 diabetic patients with nephropathy had activation of proinflammatory cytokines and signaling pathways compared to those without nephropathy $[14,15]$.

Despite the grave prognosis of patients with DKD, by using a doctor-nurse or doctor-pharmacist team to implement a structured care protocol with defined procedures and treatment targets, we were able to show dramatic benefits in increasing the likelihood of achieving multiple treatment goals, which translated to a $50 \%$ risk reduction in all event rates after 2 years $[16,17 \cdot](16)$. These results are not dissimilar to that in the Steno-2 Study [18]. In Taiwan, in a cohort of 1290 Chinese type 2 diabetic patients with normoalbuminuria followed up for 3.5 years, $4.1 \%$ of the cohort attained three or more treatment goals $(\mathrm{HbA} 1 \mathrm{c}<7 \%$, systolic $\mathrm{BP}<130 \mathrm{~mm} \mathrm{Hg}$, diastolic BP $<80 \mathrm{~mm} \mathrm{Hg}$, LDL-C $<100 \mathrm{mg} / \mathrm{dL}$; triglycerides $<150 \mathrm{mg} / \mathrm{dL}$, and HDL-C $>40 \mathrm{mg} / \mathrm{dL}$ or $50 \mathrm{mg} /$ $\mathrm{dL}$ in women) with $2 \%$ incidence of new onset of microalbuminuria. This was compared to $8 \%$ in those with one or two treatment goals (73\%) and $10 \%$ in those who did not attain any treatment goal (23\%) [19].

\section{Diabetes, Lipids, and Cancer}

Since establishing the registry, the causes of death have changed from the causes most often seen in the previous two decades. From as early as the 1970s, the World Health Organization Multicentre Vascular Disease in Diabetes Survey demonstrated the propensity of Asian populations to develop stroke and end-stage renal disease (ESRD) whereas whites were more likely to develop CHD [20]. These inter-ethnic differences have also been confirmed in the Asia Pacific Cohort Collaborative Study Group [21] and randomized controlled trials such as Action in Diabetes and Vascular Disease (ADVANCE) [22]. In the 1990s, stroke and ESRD were the leading causes of death in our Chinese diabetic patients [23]. In early 2000, with better control of BP and access to dialysis, deaths due to stroke and ESRD fell, whereas those due to CHD started to increase. With the wider usage of lipid-lowering drugs and coronary interventions, the reduced mortality from cardiovascular diseases has resulted, at least in part, in cancer becoming a more likely cause of death in our type 2 diabetic patients [6].

Compared to the Hong Kong Cancer Registry, our diabetic patients had $30 \%$ increased risk of all-site cancers in all age groups in both men and women [6]. These findings are in agreement with most meta-analysis on risk association of cancer with diabetes [24]. Using the spline analysis, we observed novel non-linear relationships between cancer risk and lipid parameters. Both low and high LDL-C levels were associated with increased cancer risk with an optimal level of $3.28 \mathrm{mmol} / \mathrm{L}$ [25], whereas patients with triglyceride level $<1.7 \mathrm{mmol} / \mathrm{L}$ also had high cancer risk. However, these risk associations were markedly attenuated in patients treated with statins [26]. In addition, there were interactive effects between low LDL-C and albuminuria on cancer risk, which were attenuated by statin use. In non-statin users, high white blood cell (WBC) count (ie, $\geq 8.2 \times 10^{9}$ counts/L) was associated with increased cancer risk, which was attenuated by RAS blockers [27]. The benefits of statins and RAS blockers on cancer risk suggest that activation of the 3-hydroxy-3-methylgutarylcoenzyme A (HMG-CoA) reductase and RAS pathways may play pivotal roles in carcinogenesis. These pharmacoepidemiologic findings were corroborated in a uninephrectomized rat model that developed proteinuria, hyperglycemia, dyslipidemia, renal dysfunction, and renal cancer in a sequential manner. These changes were accompanied by activation of the RAS, HMG-CoA reductase, insulin-like growth factor 1 (IGF1), and Akt pathways, all of which were attenuated by treatment with angiotensin-converting enzyme inhibitors [28].

\section{Glycemic Control and Cancer Risk}

Recently, a series of observational studies has raised concerns regarding the effects of blood glucose lowering drugs, notably insulin analogue, on cancer risk in diabetic 
patients [29]. Insulin resistance and hyperinsulinemia leading to dysregulation in IGF1 and steroid pathways are often proposed as factors linking diabetes, obesity, and cancer [30]. However, as early as 1956, Warburg [31] reported that cancer cells thrived better in anaerobic conditions by using glycolysis rather than tricarboxylic acid (TCA) cycle to obtain energy for cell growth and (de) differentiation. Using our diabetes registry, we were the first to report the near linear relationship between cancer risk and $\mathrm{HbA} 1 \mathrm{c}$ level, with a threshold value of $6 \%$ to $6.5 \%$. For every $1 \%$ increase in $\mathrm{HbA} 1 \mathrm{c}$, there was an $18 \%$ increased risk of cancer after adjustment for covariates and drug use during treatment. Furthermore, using a cohort study design, we observed 52\% risk reduction in cancer incidence among insulin users compared to non-users after adjustment for covariates, drug use during follow-up, and propensity score for likelihood of insulin use [32]. In a recent meta-analysis of randomized controlled trials comparing intensive blood glucose lowering versus standard treatment, for a $0.3 \%$ to $0.8 \%$ difference in $\mathrm{HbAlc}$, there was a non-significant $9 \%$ risk reduction in cancer risk in the intensive-treatment group. Therefore, findings from these published interventional studies corroborate with our observational findings in these cohort studies $(0.55 \%$ increase in $\mathrm{HbAlc}$ and $9 \%$ increased cancer risk) [33].

With better control of risk factors and aggressive management of cardio-renal complications, there are now more opportunities for cancer to develop, with an annual incidence of approximately $1 \%$ in our registry. Although results from the Action to Control Cardiovascular Risk in Diabetes (ACCORD) study have raised concerns regarding the risk-benefit ratio of intensive blood glucose lowering to HbAlc $<6.5 \%$ [34], our results suggest that the effects of intensive glycemic control need to be systematically tested, with cancer included as a primary clinical endpoint. Given the earlier age of onset of disease and high risk of exposure to carcinogens, such as chronic viral infections, tobacco, and environmental toxins in Asia, early diagnosis and intensive risk factor management could lead to major benefits on multiple endpoints [35•].

\section{Effectiveness of Drugs on Clinical Outcomes in Real Settings}

In Hong Kong, all medications are dispensed on site in the public health care setting. All dispensing data are computerized, which allows us to examine the effects of medications on clinical outcomes in a real-life setting. In this prospective cohort, $31 \%$ of patients were achieving two or more treatment goals (HbAlc $<7 \%$, BP $<130 / 80 \mathrm{~mm} \mathrm{Hg}$, LDL-C $<2.6 \mathrm{mmol} / \mathrm{L}$ ), $41 \%$ were achieving one goal, and
$28 \%$ were not achieving any goal at enrollment. After 6 years of follow-up, the former two groups had $40 \%$ and $20 \%$ risk reduction, respectively, in incident CHD compared to those who did not attain any goal [36]. These findings mirrored those reported in the randomized Steno two study, which demonstrated the marked benefits of multifactorial treatment on micro- and macrovascular complications in type 2 diabetic patients with hypertension and microalbuminuria [18].

Similarly, we were able to confirm the benefits of RAS blockers in reducing cardio-renal complications in patients with all degrees of albuminuria especially those with micro- and macroalbuminuria [9], reinforcing the findings from previous large-scale, randomized controlled trials $[37,38]$. Apart from showing the attenuating effects of statins on cancer risk, we also reported the effects of statin use in reducing new onset of DKD by $60 \%$ [39]. In a subgroup analysis, we demonstrated possible causal effects of high LDL-C on albuminuria and of low HDL$\mathrm{C}$ on eGFR. In experimental studies, urinary loss of protein can lead to over-production of low- molecularweight lipoproteins, which can cause inflammatory changes in the renal interstitium [40]. Given the close link between renal dysfunction and cardiovascular diseases, there is a need to conduct large-scale, randomized controlled trials to examine the effects of statins on multiple endpoints, including cardio-renal and cancer events in Asian populations.

In whites, there is irrefutable evidence supporting the cardioprotective effects of statins in both primary and secondary prevention trials, although similar data are lacking in Asian populations. Using this prospective database, we were able to confirm the higher risk of cardiovascular disease in Chinese type 2 diabetic patients with LDL-C $>3 \mathrm{mmol} / \mathrm{L}$ as a threshold value, whereas the risk relationship with HDL-C was linear and negative. Treatment with statins was associated with a $40 \%$ risk reduction in new onset of CHD, irrespective of baseline LDL-C level. Pending definitive evidence from randomized controlled trials, these observational data strongly advocate the use of these life-saving drugs in Asian patients [41].

Yet despite the recommendation of aspirin use in diabetic patients until recently, we have reported the paradoxical increase in risk of CHD in patients treated with aspirin for primary prevention [42]. The negative effect of aspirin on cardioprotection has recently been confirmed in randomized controlled trials [43, 44] and meta-analysis [45]. Therefore, the diabetes registry serves not only as an invaluable quality assurance tool, it also allows us to evaluate the risks and benefits of drugs on clinical outcomes in a real setting and to make novel observations for further testing. 


\section{Genotype-Phenotype Interactions}

When we set up this diabetes registry, we also sought written informed consent from our enrolled patients to donate their serum and DNA to establish a biobank for study of genotype-phenotype correlations in Chinese diabetic patients. Here, the familial clustering of diabetic nephropathy strongly suggests the importance of genetic predisposition for diabetic complications. In a subgroup analysis, we reported the independent predictive roles of genetic polymorphisms of aldose reductase [46], ACE [47], lipases and apolipoproteins [48], and protein kinase C [49] on development of cardio-renal endpoints, after controlling for covariates and use of RAS blockers. Using a panel of single nucleotide polymorphisms (SNPs) implicated in cardiovascular diseases encoding stress responses, obesity, lipid metabolism, BP control, and oxidative defenses, we applied structural equation modeling to quantify the complex phenotype-genotype interactions that explained $30 \%$ to $80 \%$ of variance of renal function [50]. Using cardiovascular diseases as outcome measures, we further observed the independent and additive effects of SNPs implicated in oxidative stress, thrombosis, endothelial dysfunction, and cytokines on cardiovascular diseases after adjustment for conventional risk factors [51, 52]. Because most of these genetic markers cannot be reflected by intermediate phenotypes such as BP or lipids, these genetic markers may be used to identify and subsequently refer subjects with a high risk for diabetic complications for intensive treatment.

\section{Multidisciplinary Care through Communication and Collaboration}

During the early stage of the quality assurance and improvement program and in collaboration with a group of primary care doctors, we pioneered a shared-care program using structured referral forms and follow-up procedures in primary and hospital clinic settings. By setting up bi-weekly complication screening sessions, we were able to re-engineer our clinic operation, systematically screen patients for risk stratification, triage them to appropriate care models, and reduce long waiting lists for new referrals [53].

By using a doctor-nurse team to deliver a structured care protocol, we have been able to reduce mortality and allevent rates by $50 \%$ to $70 \%$ in diabetic patients with multiple risk factors and renal dysfunction [17•]. In 2007, we combined the concepts of risk stratification and structured care to establish a web-based Joint Asia Diabetes Evaluation (JADE) program. This state of the art electronic portal consists of templates for data collection during annual comprehensive assessment and follow-up visits, a validated risk engine, care protocols guided by risk profiles, decision support, and matrixes showing key performance indexes (eg, percentage of patients on treatment goals or with poor risk factor control). The portal enables doctors to establish their own diabetes registry and provides summary reports with charts/diagrams to illustrate trends of risk factors control (HbAlc, BP, LDL-C, body weight) and practice tips to both care providers and patients. With patients' written informed consent, this anonymous database will contribute to a regional prospective cohort to validate the various Hong Kong Risk Equations in a larger Asian population, set benchmarks for quality of care, and promote cooperative learning to improve care standards $[54 \cdot, 55 \bullet]$.

\section{Conclusions}

By late 1990s, these complication screening services have become standard practices in all diabetes centers in public hospitals. In 2008, the Hong Kong government identified diabetes and hypertension as priority health care areas and invested heavily in primary care clinics to implement similar risk stratification and diabetes management and education programs to improve chronic care in the community.

From a research perspective, ongoing data collection and analysis of the registry has provided new insights into differences and similarities in presentation, disease progression, and outcomes between Chinese (Asian) and white populations. Results from our pharmaco-epidemiologic analysis have validated international recommendations often based on data collected from white populations. However, we have also demonstrated the phenotypic heterogeneity, predisposition to DKD, and emerging importance of cancer in Asian population that will require novel strategies to reduce these disease burdens. These epidemiologic results will provide important data for study design to ensure that the results are clinically meaningful and applicable to the Asian populations.

Finally, in this post-genome-wide association and sequencing era, well-designed cohort studies with detailed phenotypes have become invaluable resources to enable researchers to make novel and clinically meaningful discoveries. By setting up a diabetes registry accompanied by a biobank, clinician scientists are uniquely placed to contribute to the understanding of this complex disease using a genomic approach, through risk prediction, risk stratification, and personalized care in order to maximize benefits and minimize harm.

Acknowledgments We thank all the medical and nursing staff of the Prince of Wales Hospital Diabetes and Endocrine Centre for their 
professionalism and dedication. Special appreciation is made to Merck Sharpe Dohme for an educational grant that has provided partial support for analysis of the Registry and establishment of the Joint Asia Diabetes Evaluation Program. We thank our patients for allowing us to analyze this data for research and education purpose. The study was funded by the Hong Kong Foundation for Research and Development in Diabetes and Focused Investment Scheme of the Chinese University of Hong Kong. We thank Miss Nicola Brown for editing the manuscript.

Disclosure Juliana Chan is a board member of the Asia Diabetes Foundation, and is a consultant for AstraZeneca, Bristol-Myers Squibb, Daiichi-Sankyo, GlaxoSmithKline, Merck Sharp \& Dohme, Pfizer, SanofiAventis, and Qualigenics. She has received honoraria, travel expenses, and payment for development of educational presentations from AstraZeneca, Bayer, Bristol-Myers Squibb, Daiichi-Sankyo, Eli Lilly, GlaxoSmithKline, Merck Serono, Merck Sharp \& Dohme, Nestle Nutrition Institute, Novo Nordisk, Pfizer, Roche, and Sanofi-Aventis; and her institution has received research grants from pharmaceutical companies for conduct of clinical trials of anti-diabetes drugs.

Ronald CW Ma is a consultant for Pfizer and AstraZeneca and has received speaker honoraria from Sanofi-Aventis, Pfizer, Eli Lilly, and Nestle.

Peter CY Tong is a board member of the Eli Lilly Asia Diabetes Board and a consultant for Sanofi-Aventis HK and Eli Lilly HK. He has had travel expenses paid for by Takeda, MSD, Sanofi, and Eli Lilly.

Wingyee So, Rebecca Wong, and Xilin Yang report no potential conflicts of interest relevant to this article.

Open Access This article is distributed under the terms of the Creative Commons Attribution Noncommercial License which permits any noncommercial use, distribution, and reproduction in any medium, provided the original author(s) and source are credited.

\section{References}

Papers of particular interest, published recently, have been highlighted as:

\section{- Of importance}

1. Yang W, Lu J, Weng J, Jia W, Ji L, Xiao J, et al. Prevalence of diabetes among men and women in China. $\mathrm{N}$ Engl $\mathrm{J}$ Med. 2010;362:1090-101.

2. Alleyne G, Stuckler D, Alwan A. The hope and the promise of the UN Resolution on non-communicable diseases. Global Health. 6:15 doi:10.1186/1744-8603-6-15.

3. - Chan JCN, Gagliardino JJ, Baik SH, Chantelot JM, Ferreirae SRG, Hancuf N, et al. Multi-faceted determinants for achieving glycaemic control: The International Diabetes Management Practice Study (IDMPS). Diabetes Care. 2009;32:227-33. This article reports the rates of adherence to recommended care processes and treatment targets in over 10,000 diabetic patients outside America and Europe and provides insights regarding predictors related to patients, care providers and care systems for attaining HbAlc goals.

4. Piwernetz K, Home PD, Snorgaard O, Antsiferov M, StaehrJohansen K, Krans M, et al. Monitoring the targets of the St. Vincent declaration and the implementation of quality management in diabetes care: the DiabCare initiative. Diabet Med. 1993;10:371-7.

5. Yang X, So WY, Tong PC, Ma RC, Kong AP, Lam CW, et al. Development and validation of an all-cause mortality risk score in type 2 diabetes. Arch Intern Med. 2008;168:451-7.
6. So WY, Yang X, Ma RC, Kong AP, Lam CW, Ho CS, et al. Risk factors in V-shaped risk associations with all-cause mortality in type 2 diabetes-The Hong Kong Diabetes Registry. Diabetes Metab Res Rev. 2008;24:238-46.

7. Parving HH, Gall MA, Skott P, Jorgensen HE, Lokkegaard H, Jorgensen $\mathrm{F}$, et al. Prevalence and causes of albuminuria in noninsulin-dependent diabetic patients. Kidney Int. 1992;41:758-62.

8. Wu AY, Kong NC, de Leon FA, Pan CY, Tai TY, Yeung VT, et al. An alarmingly high prevalence of diabetic nephropathy in Asian type 2 diabetic patients: the MicroAlbuminuria Prevalence (MAP) Study. Diabetologia. 2005;48:1674-5.

9. So WY, Chan N, Tong PCY, Chow CC, Chan WB, Ng MCY, et al. Effect of RAAS inhibition on survival and renal outcomes in 3737 Chinese Type 2 diabetic patients. Hypertension. 2004;44:294-9.

10. Luk A, Chan JC. Diabetic nephropathy-what are the unmet needs? Diabetes Res Clin Pract. 2008;82 Suppl 1:S15-20.

11. So WY, Kong AP, Ma RC, Ozaki R, Szeto CC, Chan NN, et al. Glomerular filtration rate, cardiorenal end points, and all-cause mortality in type 2 diabetic patients. Diabetes Care. 2006;29:2046-52.

12. Yoon KH, Lee JH, Kim JW, Cho JH, Choi YH, Ko SH, et al. Epidemic obesity and type 2 diabetes in Asia. Lancet. 2006;368:1681-8.

13. Cheng AY, Kong AP, Wong VW, So WY, Chan HL, Ho CS, et al. Chronic hepatitis B viral infection independently predicts renal outcome in type 2 diabetic patients. Diabetologia. 2006;49:1777-84.

14. Wong CK, Ho AW, Tong PC, Yeung CY, Chan JC, Kong AP, et al. Aberrant expression of soluble co-stimulatory molecules and adhesion molecules in type 2 diabetic patients with nephropathy. $\mathrm{J}$ Clin Immunol. 2008;28:36-43.

15. Wong CK, Ho AW, Tong PC, Yeung CY, Kong AP, Lun SW, et al. Aberrant activation profile of cytokines and mitogen-activated protein kinases in type 2 diabetic patients with nephropathy. Clin Exp Immunol. 2007;149:123-31.

16. Leung WYS, So WY, Tong PCY, Chan NN, Chan JCN. Effects of structured care by a pharmacist-diabetes specialist team in patients with type 2 diabetic nephropathy. Am J Med. 2005;118:1414.e1421-7.

17. • Chan JCN, So WY, Yeung CY, Ko GTC, Lau IT, Tsang MW, et al. The SURE Study: Effects of Structured versus Usual care on Renal Endpoint in Type 2 diabetes: A randomized multi-centre translational study. Diabetes Care. 2009;32:977-82. This is a multicenter study that confirms the increased likelihood of attaining multiple treatment goals in type 2 diabetic patients managed by a doctor-nurse team compared to usual care and the marked reduction in incidence of end-stage renal disease and related death in those who attained three more treatment targets compared to those who did not.

18. Gaede P, Lund-Andersen H, Parving HH, Pedersen O. Effect of a multifactorial intervention on mortality in type 2 diabetes. $\mathrm{N}$ Engl J Med. 2008;358:580-91.

19. Tu ST, Chang SJ, Chen JF, Tien KJ, Hsiao JY, Chen HC, et al. Prevention of diabetic nephropathy by tight target control in an asian population with type 2 diabetes mellitus: a 4-year prospective analysis. Arch Intern Med. 2010;170:155-61.

20. Morrish NJ, Wang S, Stevens LK, Fuller JH, Keen H. Mortality and causes of death in the WHO multinational survey of vascular diseases in diabetes. Diabetologia. 2001;44:S14-21.

21. Woodward M, Zhang X, Barzi F, Pan W, Ueshima H, Rodgers A, et al. The effects of diabetes on the risks of major cardiovascular diseases and death in the Asia-Pacific region. Diabetes Care. $2003 ; 26: 360-6$.

22. Clarke PM, Glasziou P, Patel A, Chalmers J, Woodward M, Harrap SB, et al. Event rates, hospital utilization, and costs associated with major complications of diabetes: a multicountry comparative analysis. PLoS Med. 7:e1000236. 2010. 
23. Chan JCN, Cheung CK, Cheung MYF, Swaminathan R, Critchley JAJH, Cockram CS. Abnormal albuminuria as a predictor of mortality and renal impairment in Chinese patients with NIDDM. Diabetes Care. 1995;18:1013-4.

24. Seshasai SR, Kaptoge S, Thompson A, Di Angelantonio E, Gao P, Sarwar N, Whincup PH, Mukamal KJ, Gillum RF, Holme I et al: Diabetes mellitus, fasting glucose, and risk of cause-specific death. $N$ Engl J Med, 364:829-841, 2011.

25. Yang X, So WY, Ma RC, Ko GT, Kong AP, Wang Q, et al. Predicting values of lipids and white blood cell count for all-site cancer in type 2 diabetes. Endocr Relat Cancer. 2008;15:597-607.

26. Yang X, Ma RC, Yee So W, Yu LW, Kong AP, Ko GT, et al. Low triglyceride and nonuse of statins is associated with cancer in type 2 diabetes mellitus: the Hong Kong Diabetes Registry. Cancer. 2010;117:862-871.

27. Yang X, Ma RC, So WY, Ko GT, Kong AP, Zhao H, et al. White blood cell count and renin-angiotensin system inhibitors for the risk of cancer in type 2 diabetes. Diabetes Res Clin Pract. 2009. $87: 117-125$.

28. Yang X, Zhao H, Sui Y, Ma RC, So WY, Ko GT, et al. Additive interaction between the Renin-Angiotensin system and lipid metabolism for cancer in type 2 diabetes. Diabetes. 2009;58:1518-25.

29. Hernandez-Diaz S, Adami HO. Diabetes therapy and cancer risk: causal effects and other plausible explanations. Diabetologia. 2010;53:802-8.

30. Calle EE, Kaaks R. Overweight, obesity and cancer: epidemiological evidence and proposed mechanisms. Nat Rev Cancer. 2004;4:579-91.

31. Warburg O. On the origin of cancer cells. Science. 1956;123:309-14.

32. Yang X, Ko GT, So WY, Ma RC, Yu LW, Kong AP, et al. Associations of hyperglycemia and insulin usage with the risk of cancer in type 2 diabetes: the Hong Kong Diabetes Registry. Diabetes. 2010;59:1254-60.

33. Johnson JA, Bowker SL. Intensive glycaemic control and cancer risk in type 2 diabetes: a meta-analysis of major trials. Diabetologia. 2010;54:25-31.

34. Gerstein HC, Miller ME, Byington RP, Goff Jr DC, Bigger JT, Buse JB, et al. Effects of intensive glucose lowering in type 2 diabetes. N Engl J Med. 2008;358:2545-59.

35. Chan JC, Malik V, Jia W, Kadowaki T, Yajnik CS, Yoon KH, et al. Diabetes in Asia: epidemiology, risk factors, and pathophysiology. JAMA 2009;301:2129-40. This is a comprehensive review article summarizing what we know about the Asian diabetic population in terms of epidemiology, risk factors, and pathophysiology. It also highlights the importance of diabetic kidney disease, gestational diabetes, and childhood obesity in setting up a vicious cycle of diabetes begetting diabetes as well as the emerging importance of cancer as a cause of death in Asian type 2 diabetic patients.

36. Kong AP, Yang X, Ko GT, So WY, Chan WB, Ma RC, et al. Effects of treatment targets on subsequent cardiovascular events in Chinese patients with type 2 diabetes. Diabetes Care. 2007;30:953-9.

37. Brenner BM, Cooper ME, De Zeeuw D, Keane WF, Mitch WE, Parving HH, et al. Effects of Losartan on renal and cardiovascular outcomes in patients with type 2 diabetes and nephropathy. $\mathrm{N}$ Engl J Med. 2001;345:861-9.

38. Parving HH, Lehnert H, Brochner-Mortensen J, Gomis R, Anderesen S, Arner P. For the irbesartan in patients with type 2 diabetes and Microalbuminuria Study Group: the effect of irbesartan on the development of diabetic nephropathy in patients with type 2 diabetes. N Engl J Med. 2001;345:870-8.

39. Luk AO, Yang X, Ma RC, Ng VW, Yu LW, Lau WW, et al. Association of statin use and development of renal dysfunction in type 2 diabetes - the Hong Kong Diabetes Registry. Diabetes Res Clin Pract. 2010;88:227-33.
40. Yang XL, So WY, Ma RCW, Ko GTC, Kong APS, Lam CWK, et al. Effects of albuminuria and renal dysfunction on development of dyslipidaemia in Type 2 diabetes-Hong Kong Diabetes Registry. Nephrology, Dialysis, Transplantation. 2008;23:2834 2840.

41. Ting RZ, Yang X, Yu LW, Luk AO, Kong AP, Tong PC, et al. Lipid control and use of lipid-regulating drugs for prevention of cardiovascular events in Chinese type 2 diabetic patients: a prospective cohort study. Cardiovasc Diabetol. 2010;9:77.

42. Leung WY, So WY, Stewart D, Lui A, Tong PC, Ko GT, et al. Lack of benefits for prevention of cardiovascular disease with aspirin therapy in type 2 diabetic patients-a longitudinal observational study. Cardiovasc Diabetol. 2009;8:57.

43. Belch J, MacCuish A, Campbell I, Cobbe S, Taylor R, Prescott R, et al. The prevention of progression of arterial disease and diabetes (POPADAD) trial: factorial randomised placebo controlled trial of aspirin and antioxidants in patients with diabetes and asymptomatic peripheral arterial disease. BMJ. 2008;337: a1840.

44. Ogawa H, Nakayama M, Morimoto T, Uemura S, Kanauchi M, Doi $\mathrm{N}$, et al. Low-dose aspirin for primary prevention of atherosclerotic events in patients with type 2 diabetes: a randomized controlled trial. JAMA. 2008;300:2134-41.

45. Zhang C, Sun A, Zhang P, Wu C, Zhang S, Fu M, et al. Aspirin for primary prevention of cardiovascular events in patients with diabetes: A meta-analysis. Diabetes Res Clin Pract. 2010;87:211-8.

46. So WY, Wang Y, Ng MC, Yang X, Ma RC, Lam V, et al. Aldose reductase genotypes and cardio-renal complications - a 8-year prospective analysis of 1074 Type 2 diabetic patients. Diabetes Care. 2008;31:2148-53.

47. Wang $\mathrm{Y}, \mathrm{Ng} \mathrm{MC}$, So WY, Tong PC, Ma RC, Chow CC, et al. Prognostic effect of insertion/deletion polymorphism of the ACE gene on renal and cardiovascular clinical outcomes in Chinese patients with type 2 diabetes. Diabetes Care. 2005;28:348-54.

48. Baum L, Ng MC, So WY, Lam VK, Wang Y, Poon E, et al. Effect of hepatic lipase $-514 \mathrm{C} \rightarrow \mathrm{T}$ polymorphism and its interactions with apolipoprotein $\mathrm{C} 3-482 \mathrm{C} \rightarrow \mathrm{T}$ and apolipoprotein $\mathrm{E}$ exon 4 polymorphisms on the risk of nephropathy in Chinese type 2 diabetic patients. Diabetes Care. 2005;28:1704-9.

49. Ma RC, Tam CH, Wang Y, Luk AO, Hu C, Yang X, et al. Genetic variants of the protein kinase $\mathrm{C}$-beta 1 gene and development of end-stage renal disease in patients with type 2 diabetes. JAMA. 2010;304:881-9.

50. Song XY, Lee SY, Ma RC, So WY, Cai JH, Tam C, et al. Phenotype-genotype interactions on renal function in type 2 diabetes: an analysis using structural equation modelling. Diabetologia. 2009;52:1543-53.

51. Wang Y, Luk AO, Ma RC, So WY, Tam CH, $\mathrm{Ng} \mathrm{MC}$, et al. Independent predictive roles of eotaxin Ala23 $\mathrm{Thr}$, paraoxonase 2 Ser311Cys and beta-adrenergic receptor Trp64Arg polymorphisms on cardiac disease in Type 2 Diabetes-an 8-year prospective cohort analysis of 1297 patients. Diabet Med. 2010;27:376-83.

52. Luk AO, Wang Y, Ma RC, Tam $\mathrm{CH}, \mathrm{Ng} \mathrm{MC}$, Lam $\mathrm{V}$, et al. Predictive role of polymorphisms in interleukin-5 receptor alphasubunit, lipoprotein lipase, integrin A2 and nitric oxide synthase genes on ischemic stroke in type 2 diabetes-An 8 -year prospective cohort analysis of 1327 Chinese patients. Atherosclerosis. 2011;215:130-135.

53. Chan JCN, Lau MSW, Wong YM, Chow CC, Yeung VTF, Loo KM, et al. Delivery of diabetes care - the experience at the Prince of Wales Hospital. In Hospital Authority Quality Bulletin. 1997:3-21

54. - Chan JCN, So WY, Ko G, Tong PCT, Yang XL, Ma RCW, et al. The Joint Asia Diabetes Evaluation (JADE) program: a web-based program to translate evidence to clinical practice in type 2 diabetes. Diabet Med 2009;26:693-9. This is a translational program that validates the use of various risk equations to predict 
multiple endpoints in Asian populations and discusses the challenges and opportunities in implementing chronic care.

55. • Ko GT, So WY, Tong PC, Le Coguiec F, Kerr D, Lyubomirsky $\mathrm{G}$, et al. From design to implementation - the Joint Asia Diabetes Evaluation (JADE) program: a descriptive report of an electronic web-based diabetes management program. BMC Med Inform Decis Mak. 2010;10:26. This is a translational program that uses state of the art information technology to combine the concept of risk stratification and protocol-driven care to enable doctors to establish a diabetes registry for quality assurance and use of a multidisciplinary team to implement structured care.

56. Yang X, So WY, Kong AP, Ma RC, Ko GT, Ho CS, et al. Development and validation of a total coronary heart disease risk score in type 2 diabetes mellitus. Am J Cardiol. 2008;101:596-601.

57. Ma RC, So WY, Yang X, Yu LW, Kong AP, Ko GT, et al. Erectile dysfunction predicts coronary heart disease in type 2 diabetes. J Am Coll Cardiol. 2008;51:2045-50.

58. Tong PCY, Kong APS, So WY, Ng MHL, Yang XL, Ozaki R, et al. Hematocrit, independent of chronic kidney disease, predicts adverse cardiovascular outcomes in Chinese patients with type 2 diabetes mellitus. Diabetes Care. 2006;29:2439-44.

59. Tong PC, Kong AP, So WY, Yang X, Ng MC, Ho CS, et al. Interactive effect of retinopathy and macroalbuminuria on all-cause mortality, cardiovascular and renal end points in Chinese patients with Type 2 diabetes mellitus. Diabet Med. 2007;24:741-6.

60. Tong PCY, Lee KF, So WY, Ng MCY, Chan WB, Lo MKW, et al. Association of white blood cell counts with macrovascular and microvascular complications in Chinese patients with type 2 diabetes. Diabetes Care. 2004;27:216-22.

61. Lo MKW, Lee KF, Chan N, Leung W, Ko G, Chan WB, et al. Effects of gender, Helicobacter pylori (HP) and hepatitis B virus serology status on cardiovascular and renal complications in Chinese Type 2 diabetic patients with overt nephropathy. Diab Obes Metab. 2004;6:223-30.

62. Yang X, Ma RC, So WY, Kong AP, Ko GT, Ho CS, et al. Development and validation of a risk score for hospitalization for heart failure in patients with Type 2 diabetes mellitus. Cardiovasc Diabetol. 2008;7:9.
63. Yang X, So WY, Kong AP, Ho CS, Lam CW, Stevens RJ, et al. Development and validation of stroke risk equation for Hong Kong Chinese patients with type 2 diabetes: the Hong Kong Diabetes Registry. Diabetes Care. 2007;30:65-70.

64. Yang X, So WY, Ma RC, Ko GT, Kong AP, Ho CS, et al. Thresholds of risk factors for ischemic stroke in type 2 diabetic patients with and without albuminuria-A non-linear approach. Clin Neurol Neurosurg. 2008;110:701-709

65. Yang X, Kong AP, So WY, Ma RC, Ho CS, Lam CW, et al. Effects of chronic hyperglycaemia on incident stroke in Hong Kong Chinese patients with type 2 diabetes. Diabetes Metab Res Rev. 2007;23:220-6.

66. Yang X, Ko GT, So WY, Ma RC, Kong AP, Lam CW, et al. Additive interaction of hyperglycaemia and albuminuria on risk of ischemic stroke in type 2 diabetes mellitus-Hong Kong Diabetes Registry. Diabetes Care. 2008;31:2294-2300.

67. Luk AO, So WY, Ma RC, Kong AP, Ozaki R, Ng VS, et al. Metabolic syndrome predicts new onset of chronic kidney disease in 5,829 patients with Type 2 diabetes: a 5-year prospective analysis of the Hong Kong Diabetes Registry. Diabetes Care. 2008;31:2357-61.

68. Yang XL, So WY, Kong AP, Clarke P, Ho CS, Lam CW, et al. End-stage renal disease risk equations for Hong Kong Chinese patients with type 2 diabetes: Hong Kong Diabetes Registry. Diabetologia. 2006;49:2299-308.

69. Yang XL, So WY, Kong AP, Ho CS, Lam CW, Ng MH, et al. Modified end-stage renal disease risk score for Chinese type 2 diabetic patients-the Hong Kong Diabetes Registry. Diabetologia. 2007;50:1348-50.

70. Yang X, So WY, Ma RC, Yu LW, Ko GT, Kong AP, et al. Use of sulphonylurea and cancer in type 2 diabetes-The Hong Kong Diabetes Registry. Diabetes Res Clin Pract. 2010;90:343-51.

71. Yang X, So WY, Ma RC, Kong AP, Lee HM, Yu LW, et al. Low HDL Cholesterol, Metformin Use and Cancer Risk in Type 2 Diabetes - the Hong Kong Diabetes Registry. Diabetes Care. 2011;34:375-380. 